\title{
Breeding structure of Drosophila buzzatii in relation to competition in prickly pears (Opuntia ficus-indica)
}

\author{
JE Quezada-Díaz, H Laayouni, A Leibowitz, \\ M Santos*, A Fontdevila \\ Departament de Genética $i$ de Microbiologia, Universitat Autònoma de Barcelona, \\ 08193 Bellaterra, Barcelona, Spain
}

(Received 15 October 1996; accepted 22 April 1997)

\begin{abstract}
Summary - Rotting Opuntia ficus-indica fruits (prickly pears) are used as breeding sites for up to four Drosophila species ( $D$ melanogaster, $D$ simulans, $D$ buzzatii and $D$ hydei) in southern Spain. A field experiment showed that the larvae of $D$ buzzatii are resource limited in Opuntia fruits available for oviposition for $108 \mathrm{~h}$. Experimental fruits infested with $D$ larvae were divided into two halves; the larvae in one half were allowed to develop normally, while those in the other half were provided with extra food. Approximately five times as many $D$ buzzatii emerged from the supplemented as from the control halves, and the flies emerging from the supplemented halves were, on average, larger than those emerging from the control halves. $F$-statistics were estimated from allozyme data for the $D$ buzzatii flies. The values obtained from the supplemented halves, coupled with computer simulations to compare these estimates with the expected values generated by a limited number of mating pairs contributing progeny to a fruit, suggest an effective size of about 30 individuals. Even though $95 \%$ bootstrap confidence intervals for $F_{\text {IS }}$ estimates comparing the supplemented and control halves do not overlap, computer simulations suggest that we cannot support the hypothesis that selection is acting on allozyme variation.
\end{abstract}

body size / cactophilic Drosophila / competition / density-dependent mortality / population structure

Résumé - Structure génétique des populations de Drosophila buzzatii en situation de compétition dans les figues de barbarie (Opuntia ficus-indica). Les fruits pourris d'Opuntia ficus-indica (figues de Barbarie) sont utilisés comme sites de reproduction par quatre espèces de drosophiles (D melanogaster, D simulans, D buzzatii et $\mathrm{D}$ hydei) dans le sud de l'Espagne. Une expérimentation sur le terrain a montré que les larves de $\mathrm{D}$ buzzatii ont des ressources limitées dans les fruits d'Opuntia disponibles pour la ponte pendant 108 h. Des fruits expérimentaux infestés de larves de drosophiles ont été divisés en deux moitiés : dans la première, les larves ont pu se développer normalement et, dans la seconde,

* Correspondence and reprints 
on a ajouté de la nourriture. $\grave{A}$ peu près cinq fois plus de $\mathrm{D}$ buzzatii sont sorties des moitiés complémentées en comparaison aux moitiés de référence, et les mouches sortant des moitiés complémentées ont été en moyenne plus grandes que celles sortant des moitiés de référence. Des statistiques $F$ ont été estimées à partir de données sur allozymes pour les mouches $\mathrm{D}$ buzzatii. Les valeurs obtenues à partir des moitiés supplémentées, couplées avec des simulations sur ordinateur pour comparer ces estimées avec les valeurs espérées générées par un nombre limité d'accouplements contribuant au peuplement d'un fruit suggèrent un effectif efficace d'environ 30 individus. Même si les intervalles de confiance de $F_{\mathrm{IS}}$ donnés par la méthode de bootstrap pour les moitiés supplémentées et de référence ne se recouvrent pas, les simulations ne permettent pas d'appuyer l'hypothèse selon laquelle la sélection s'exerce sur la variation allozymique.

taille / drosophile cactophile / compétition / mortalité / structure de population

\section{INTRODUCTION}

Populations of many organisms, particularly insects, are subdivided in the sense that females lay eggs in discrete and ephemeral resources, each used as a breeding site by a small number of individuals (Heed, 1968; Jaenike and Selander, 1979; Shorrocks, 1982; Brncic, 1983; Lacy, 1983; Hoffmann et al, 1984; Santos et al, 1989; Thomas and Barker, 1990; Santos, 1997). A strong motivation to study the effects of such a population structure relates to the pervasive idea that environmental heterogeneity - arising because selection proceeds in different directions in different places, because there are complementary interactions among genotypes, or because there is an aggregated distribution of eggs over patches - can maintain genetic heterogeneity (Levene, 1953; Hoffmann and Nielsen, 1985; Hedrick, 1986; Gillespie and Turelli, 1989; Gillespie, 1991; Dytham and Shorrocks, 1992, 1995). A basic ingredient in most genetic models is the existence of crowded conditions within patches (ie, selection is 'soft', meaning that density regulation occurs within each patch separately). If competition is absent, environmental heterogeneity might be irrelevant to explain genetic variation.

The presence of competition in natural populations of Drosophila has been inferred in several cases (eg, Fellows and Heed, 1972; Atkinson, 1979; Prout and Barker, 1989), but a clear experimental demonstration was first provided by Grimaldi and Jaenike (1984). These authors collected mushrooms infested with larvae and divided each mushroom into two; the larvae in one half were allowed to develop normally, while those in the other half were provided with extra food (see also Jaenike and James, 1991). They showed that there is densitydependent mortality in natural populations, and that flies emerging from halves of supplemented mushrooms are larger than flies emerging from control halves. An important conclusion to be obtained from this experiment is that in natural populations of Drosophila there is the opportunity for selection (Crow, 1958; Arnold and Wade, 1984). From an evolutionary perspective, however, the important point is not to show that there is opportunity for selection, but that selection does indeed differentially affect the various genotypes.

We report here an experiment designed to investigate the incidence of competition in Opuntia ficus-indica fruits (prickly pears) in the field, together with an analysis of genetic diversity for the Drosophila buzzatii (Patterson and Stone) flies that emerged from natural substrates. Adults of this species have been reared from 
rotting Opuntia cladodes, which are not significantly utilized as breeding sites by other drosophilids in the Old World (at least during the summer months, Santos et al, 1988, 1992). In contrast to this, the Opuntia fruits can be exploited by other Drosophila species in southern Spain. These fruits are sweet, fleshy, frequently visited by Drosophila adults after falling from the plant, and very easy to manipulate experimentally. Although they are individually small (from approximately 30 to $90 \mathrm{~g}$ of wet weight), 'en masse' they can form habitats of considerable size. We do not have an estimate of the relative contributions of Opuntia fruits and cladodes to the total population density of $D$ buzzatii, but during the fruit season (from August to November in southern Spain) it is quite likely that a significant proportion of $D$ buzzatii flies come from Opuntia fruits. We investigated the allozyme genotypes of $D$ buzzatii emerging from the fruits, and obtained estimates of $F$-statistics. Because under field conditions we are never sure of what fraction of the genetic differentiation is attributable to drift (founder events of individual patches) or to selection, the flies raised from halves of supplemented fruits (= 'non-limited resource', see below) were used to obtain empirical distributions of $F$-statistics likely to be due to drift. Measures of inbreeding were then used to estimate the effective number of parents contributing gametes to each fruit, and to see whether or not there is genetic differentiation between breeding sites as a result of selection.

\section{Materials and methods}

\section{Description of collections}

Samples were collected in September 1993 from a disused Opuntia ficus-indica plantation (Carboneras, SE Spain), described in detail elsewhere (Ruiz et al, 1986). At that time of the year there are abundant Opuntia fruits which are exploited by $D$ melanogaster, $D$ simulans, $D$ buzzatii, and $D$ hydei.

On 3 September, 300 undamaged mature fruits were harvested from the Opuntia stems, labelled with coloured bands, and placed at random in the experimental area on 4 September after cutting a small slice at the top to allow for oviposition by Drosophila females. After various periods of time in the field these fruits were recollected and placed separately in jars on a bed of sand, covered with gauze. After $24 \mathrm{~h}, 30$ labelled fruits were collected. After $48 \mathrm{~h}$, another 30 fruits were collected and divided in half longitudinally. One half of each fruit ('control' half) was left untreated while half of a fresh, uncolonized fruit, was added to the other 'supplemented' ('= non-limited resource') half. This approximately doubled the wet mass of food available to larvae. The same procedure was followed for an additional sample of 30 fruits collected after $72 \mathrm{~h}$. Finally, on 9 September we randomly collected 124 fruits out of the remaining 210 fruits that had been left in the field for $108 \mathrm{~h}$. Control and supplemented halves were produced for 63 of those fruits, whereas the remaining 61 were placed into separate jars without cutting. These fruits served as the control for the cutting treatment.

The experimental fruits were kept at room temperature $\left(22-27^{\circ} \mathrm{C}\right)$ in the makeshift laboratory near the field site and checked regularly for emergent adults. From the time of first adult emergence (13 September), all jars were examined daily and emerged adults were fixed in a 3:1 mixture of alcohol and glycerol except 
$D$ buzzatii flies, which were kept alive in vials containing $5 \mathrm{~mL}$ of standard cornmealagar-yeast food.

$D$ melanogaster and $D$ simulans males were distinguished by the differences in their external genitalia (Sturtevant, 1919). No attempt was made to distinguish between females of these two species and their numbers were grouped together into a single class. For each species that emerged from the two halves of the 63 fruits that remained in the field for $108 \mathrm{~h}$, the wing length of up to five males per collection was measured (see Leibowitz et al, 1995). Wing length was used as an index of adult body size because it is a more convenient measure when flies can be killed. The average wing length from each control and supplemented half fruit was calculated by weighting the mean of each collection by the number of males of each species in that collection.

\section{Allozyme electrophoresis}

From most of the $108 \mathrm{~h}$ Opuntia fruits that yielded $D$ buzzatii flies, a random sample of individuals was assayed for four polymorphic enzyme loci (Est-2, Aldox, Pept-2 and $A d h-1)$. Details of the electrophoretic techniques, allele nomenclature [standardized following Barker and Mulley (1976), and Barker et al (1986)], chromosome mapping, and gametic associations between these loci and between them and the polymorphic inversions in the population of Carboneras, are given elsewhere (Quezada-Díaz et al, 1992; Quezada-Díaz, 1993; Betrán et al, 1994). Briefly, Est-2 segregates for five alleles, and the other three loci segregate for two alleles each. Est-2 and Aldox are linked to the inversions on the second chromosome, while Pept-2 is outside the inverted fragments. There are strong linkage disequilibria (sensu Lewontin and Kojima, 1960) between alleles of Est-2 and Aldox with the second chromosome arrangements. Thus, alleles Est-2 ${ }^{\mathrm{a}}$ and $E s t-2^{\mathrm{b}}$ are segregating within the gene arrangements $2 s t$ and $2 j$, with the former allele at higher frequency in $2 s t$ and the latter in higher frequency in $2 j$. Allele Est-2 ${ }^{c+}$ is fixed in the gene arrangement $2 j q^{7}$, and alleles $E s t-2^{\mathrm{c}}$ and $E s t-\mathscr{2}^{\mathrm{d}}$ are only present in the inversion $2 j z^{3}$. Allele Aldox ${ }^{\mathrm{b}}$ is associated with 2st. Adh-1 is located on the third chromosome which lacks polymorphic inversions (Labrador et al, 1990).

\section{Statistical analyses for the allozyme data}

Analyses of allelic frequencies and the calculation of $F$-statistics using the methods of Weir (1990) were accomplished with the GENEPOP (v. 1.2) population genetics software (Raymond and Rousset, 1995).

Associations among alleles at two loci were measured by the composite digenic disequilibrium coefficient $\Delta_{\mathrm{AB}}$ (Weir and Cockerham, 1989; Weir, 1990). Alleles other than Est-2 $2^{\mathrm{a}}$ were grouped together into a single class. This coefficient is equal to zero if the allelic state at one locus is not correlated with that at another. 


\section{RESULTS}

\section{Evidence of competition in natural substrates}

A total of 34745 individuals of the four Drosophila species emerged from the experimental fruits of Opuntia ficus-indica $(39.6 \% \mathrm{D}$ melanogaster, $54.4 \% \mathrm{D}$ simulans, $4.3 \% \mathrm{D}$ buzzatii and $1.6 \% \mathrm{D}$ hydei). Table I shows their average numbers per fruit, together with Wilcoxon matched-pair signed-rank tests (Siegel and Castellan, 1988) comparing the number of flies in each half. After $108 \mathrm{~h}$ in the field, approximately five times as many $D$ buzzatii emerged from the supplemented as from the control halves (only $187 \mathrm{D}$ buzzatii emerged from the control halves, whereas 845 emerged from the supplemented halves). A potential problem with 'the cutting treatment' might be that, for any reason (eg, control halves dried-out quicker), a lower number of adult flies emerged from the control fruits. A comparison of the average number of males and females ( $D$ melanogaster $/ D$ simulans females were pooled) of Drosophila species that emerged from the $108 \mathrm{~h}$ whole fruits with twice as many emerging from the $108 \mathrm{~h}$ control halves suggests that this is probably not the case here (WilcoxonMann-Whitney tests ranged from $z=0.03, P=0.972$; for $D$ melanogaster males, to $z=1.18, P=0.236$; for $D$ simulans males). Except for $D$ hydei, the Spearman rank correlations between the emergence numbers were positive and statistically significant for all pairs of species in the $108 \mathrm{~h}$ supplemented halves. However, in both the $108 \mathrm{~h}$ control halves and $108 \mathrm{~h}$ whole fruits the $D$ buzzatii-D melanogaster and $D$ buzzatii- $D$ simulans rank correlations were very low and statistically nonsignificant, probably owing to the increase in mortality suffered by $D$ buzzatii.

The only differences in size distributions between flies emerging from the $108 \mathrm{~h}$ control and supplemented halves were found for D buzzatii (table II). Because up to five males per fruit per collection were measured for each species (see Material and methods), in the $108 \mathrm{~h}$ control halves we had an index of body size for most of the $D$ buzzatii males that emerged. Therefore, we could carry out a multiple regression analysis of the effect of each species' density (estimated as the number of males that emerged in a given fruit) on the individual wing length of each $D$ buzzatii male. Forward stepwise regression coefficients were statistically significant for $D$ buzzatii $\left(\beta_{\text {intra }}=-0.018 P=0.008\right), D$ simulans $\left(\beta_{\text {inter }}=-0.004, P<0.001\right)$ and $D$ melanogaster $\left(\beta_{\text {inter }}=0.002, P=0.006\right)$, the negative regression for $D$ buzzatii suggesting that intraspecific competition is occurring within the breeding sites. The negative correlation between the wing length of $D$ buzzatii and the number of $D$ simulans might also indicate the occurrence of interspecific competition, but some care must be taken with such an interpretation because it is possible that conditions that enhance the numbers of $D$ simulans may adversely affect the body size of $D$ buzzatii. Conversely, some conditions may enhance the numbers of $D$ melanogaster and the body size of $D$ buzzatii, which could explain the highly significant positive correlation found between both variables.

Figure 1 shows the number of male flies that emerged from the $108 \mathrm{~h}$ control and supplemented fruits through time. It is obvious that $D$ melanogaster and $D$ simulans have shorter development times than $D$ buzzatii and $D$ hydei, which clearly suggests that they would always be at a competitive advantage at high larval densities (see Discussion). 


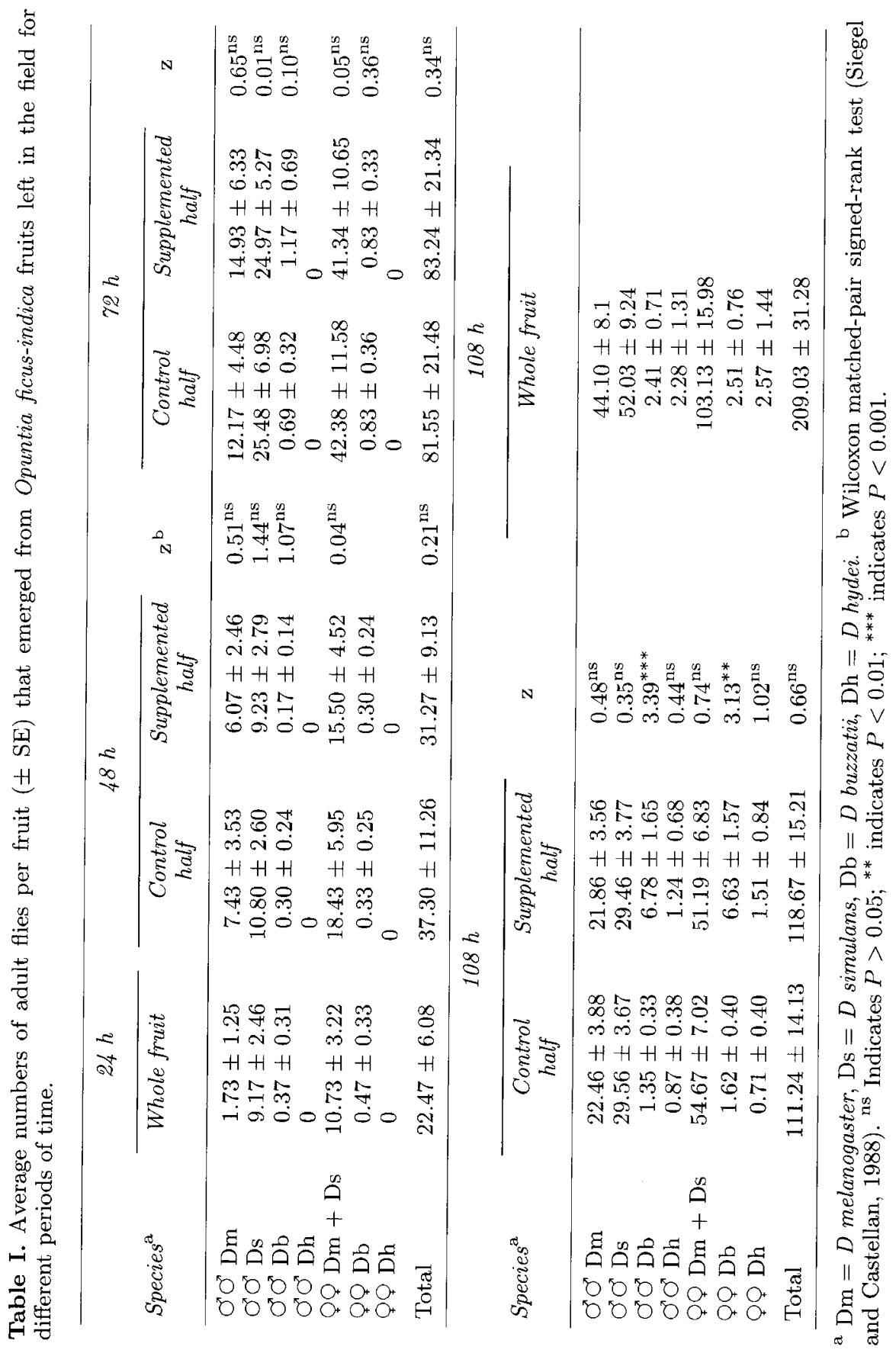


Table II. Mean wing length $(\mathrm{mm} \pm \mathrm{SD})$ of males emerged from control and supplemented halves of $108 \mathrm{~h}$ fruits.

\begin{tabular}{|c|c|c|c|c|}
\hline \multirow[b]{2}{*}{ Species } & \multicolumn{2}{|c|}{$108 \mathrm{~h}$} & \multirow[b]{2}{*}{$t_{s}^{b}$} & \multirow[b]{2}{*}{$\mathrm{df}$} \\
\hline & $\begin{array}{l}\text { Control } \\
\text { half }\end{array}$ & $\begin{array}{l}\text { Supplemented } \\
\text { half }\end{array}$ & & \\
\hline$\sigma^{\pi} \sigma^{\pi} \mathrm{Dm}$ & $1.901 \pm 0.069$ & $1.905 \pm 0.053$ & $0.65^{\mathrm{ns}}$ & 40 \\
\hline$\sigma^{\top} \sigma^{\top} \mathrm{Ds}$ & $1.721 \pm 0.055$ & $1.721 \pm 0.031$ & $0.21^{\mathrm{ns}}$ & 50 \\
\hline$\sigma^{2} \sigma^{7} \mathrm{Db}$ & $1.863 \pm 0.131$ & $1.951 \pm 0.089$ & $2.92^{*}$ & 13 \\
\hline$\sigma^{\prime} \sigma^{\prime} \mathrm{Dh}$ & $2.537 \pm 0.131$ & $2.596 \pm 0.062$ & $1.60^{\mathrm{ns}}$ & 3 \\
\hline
\end{tabular}

${ }^{\mathrm{a}} \mathrm{Dm}=D$ melanogaster, $\mathrm{Ds}=D$ simulans, $\mathrm{Db}=D$ buzzatii, $\mathrm{Dh}=D$ hydei. ${ }^{\mathrm{b}}$ Paired t-test. ${ }^{\text {ns }}$ Indicates $P>0.05 ;{ }^{*}$ indicates $P<0.05$.

\section{Analysis of population structure}

Table III presents summary $F$-statistics for the $D$ buzzatii flies that emerged from the $108 \mathrm{~h}$ Opuntia fruits (the raw data are available upon request to the corresponding author). For selectively neutral loci, the extent of genetic differentiation of the subpopulations in the present situation, where there is only one round of drift and random mating in the population at large (Quezada-Díaz et al, 1992; Barbadilla et al, 1994), is characterized by $N_{\mathrm{e}}$, the effective number of locally breeding adults (Wade and McCauley, 1988). All confidence intervals for $F$ values in the $108 \mathrm{~h}$ supplemented fruits included zero, which suggests that $N_{\mathrm{e}}$ is relatively large (see below). On the other hand, $F_{\mathrm{IS}}$ and $F_{\mathrm{ST}}$ values were different from zero in the $108 \mathrm{~h}$ control fruits, indicating that there is an excess of heterozygotes within, and a substantial differentiation among, limited resource fruits. The confidence intervals for $F_{\mathrm{IS}}$ do not overlap, and this could be taken as a real difference between the supplemented and the control fruits. However, some caution is needed with this interpretation because it could be argued that with four loci (as here), and under the null hypothesis $H_{0}: F_{\mathrm{IS}}=0$, estimates of this parameter are negative for all loci with a probability of $(1 / 2)^{4}=0.0625$, and zero will be included in the confidence interval. Raymond and Rousset (1995b) have recently stressed that bootstrap resampling to build a confidence interval is incorrect when the number of loci is small.

Exact tests for population differentiation (Raymond and Rousset, 1995a, b) comparing control and supplemented fruits provided no evidence for allelic heterogeneity at any locus. Analysis of two-locus linkage disequilibrium coefficients showed only eight significant disequilibria out of 179 possible comparisons. Four of these pairs have both members located on the second chromosome, and the other four involved the $A d h-1$ locus. Thus, no clear patterns were found, and this result could be taken as another reflection of large effective population size within Opuntia fruits (see below). 

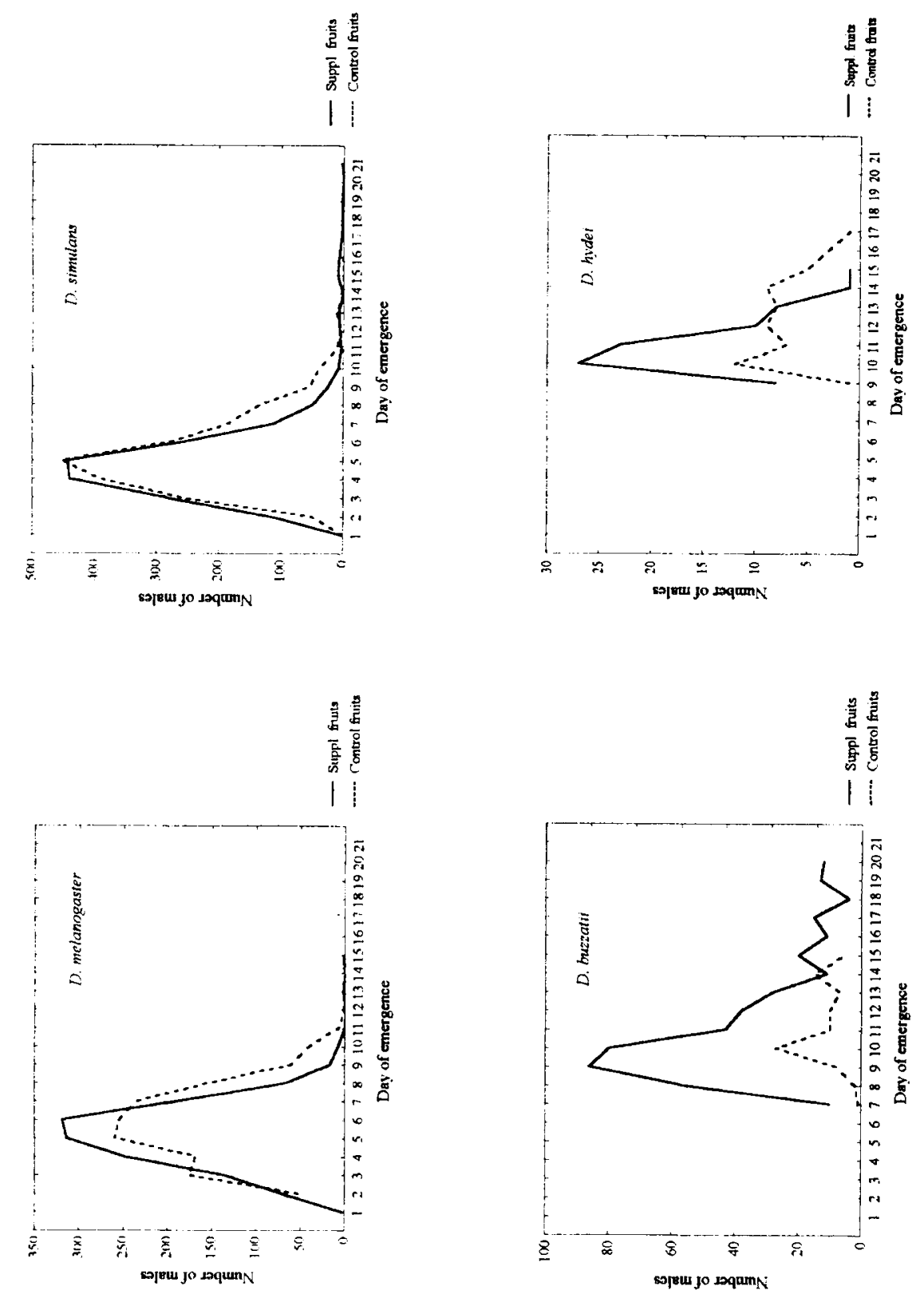

Fig 1. Distribution of emergences through time in $108 \mathrm{~h}$ control and supplemented $O$ ficus-indica fruits for the four Drosophila species. 


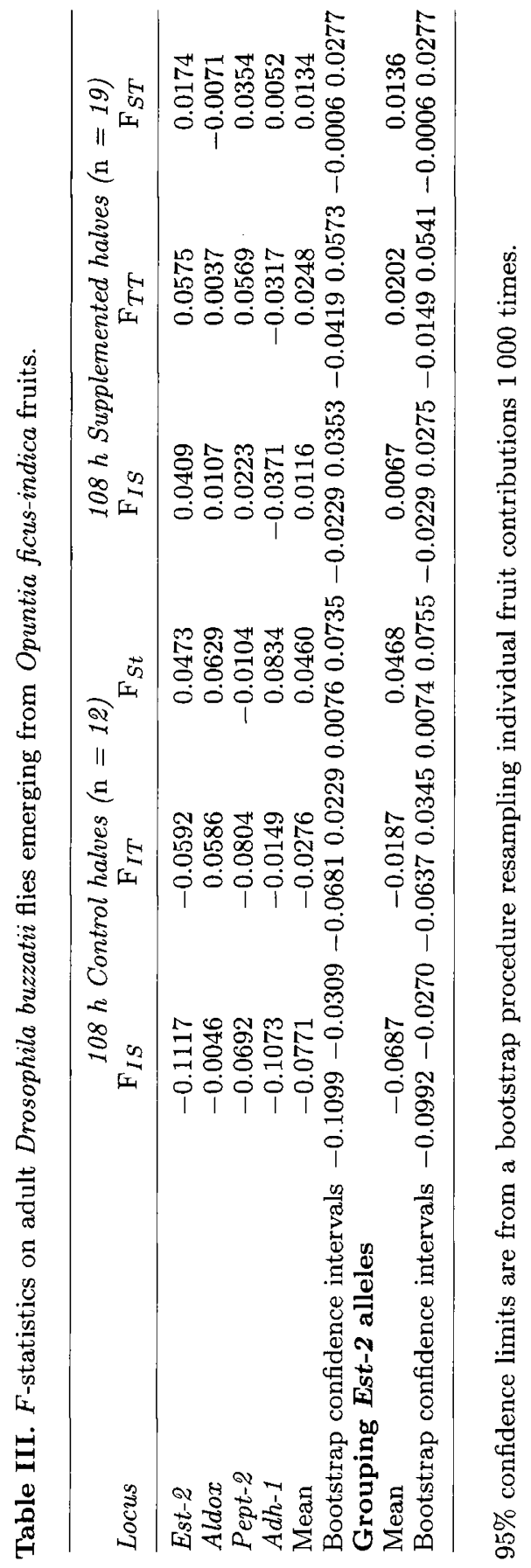




\section{Estimate of the number of parents breeding on a single fruit}

Given that flies from the supplemented halves have developed in 'non-limited resources', it is important to recall that the corresponding $F$-values in table III do not mix drift and selection but probably reflect the sampling effect. Therefore, we used computer simulations to compare $F$-statistics from supplemented fruits with the expected values generated by various numbers of mating pairs contributing to a breeding site. The main steps of our reasoning for disentangling the effects of drift and selection are summarized in figure 2. Different numbers of mating pairs were selected randomly to contribute to 19 breeding sites, and a number of offspring equal to that obtained for the supplemented fruits (between 5 and 80 individuals per fruit) was sampled at random from each breeding site. Even though theoretical predictions about the expected $F$-values could be easily made from the above assumptions (see below), we think it may be useful to have an idea of the standard deviations of their distributions in this particular case (ie, equal number of fruits and emerging adults than in the actual sample). $F$-statistics were calculated according to the methods of Weir (1990), and 100 simulations were undertaken for each set of conditions. The interactive matrix algebra program MATLAB (V 4.0 for Windows) was used for computations on a 486 (66 Mhz) PC-compatible. For simplicity, we considered four biallelic loci (alleles other than Est-2 $2^{2}$ were grouped into a single class) with allele frequencies in the total population equal to those estimated from the supplemented halves. Estimates of $F$-statistics after grouping alleles are also given at the bottom of table III.

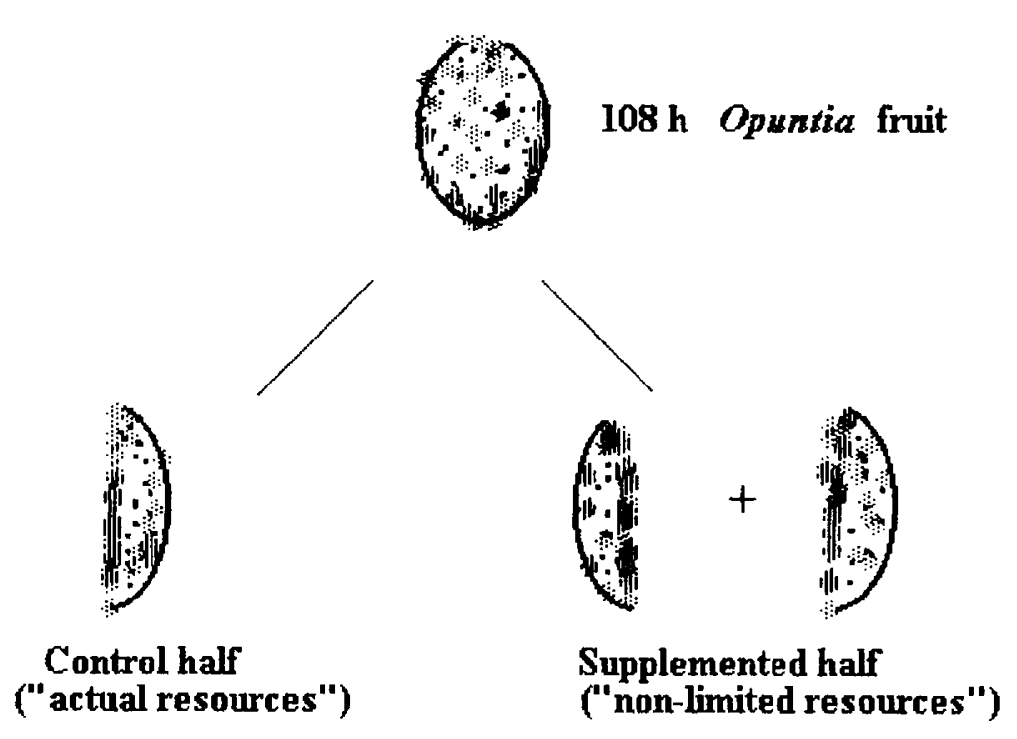

Fig 2. Experimental procedure and simulation steps for disentangling the effects of drift and selection on $F$-statistics. Simulation steps: 1) estimate the number of founders from the supplemented halves; 2 ) build a confidence interval for $F_{\text {IS }}$ in the control fruits due to 'drift'; 3) estimate the probability of obtaining the actual $F_{\mathrm{IS}}(=-0.0687)$. 


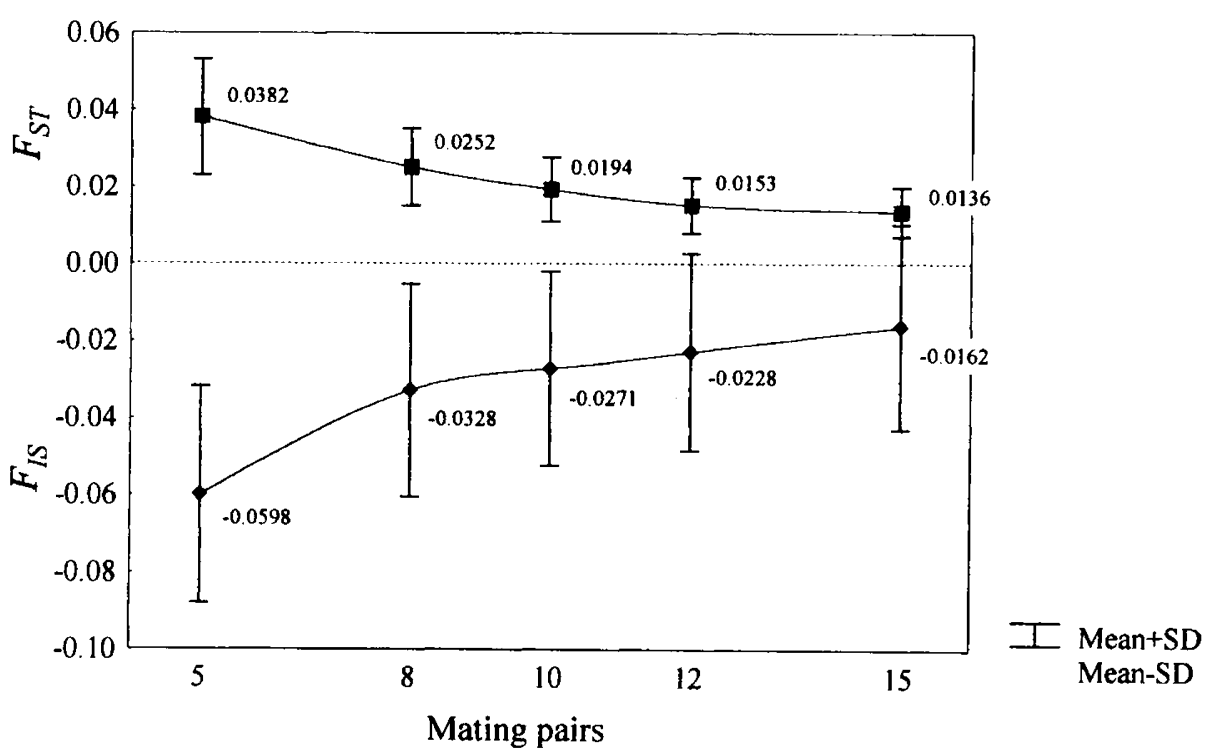

Fig 3. Expected values for $F_{\mathrm{ST}}$ and $F_{\mathrm{IS}}$ estimates of supplemented fruits when different numbers of mating pairs taken at random from the total population contribute to the progeny of each fruit. Each point represents the mean ( \pm SD) of 100 simulations. The points have been connected by cubic spline interpolation to enhance visibility.

$F_{\mathrm{ST}}$ and $F_{\text {IS }}$ values approach zero (fig 3 ) as more mating pairs contribute to a site, and comparisons with the actual values in table III (ie, those from the supplemented halves) suggest that at least 15 females oviposit on a site. The expected values of $F_{\text {IS }}$ in figure 3 could also be approximated by $-1 /\left(2 N_{e}-1\right)$ (Kimura and Crow, 1963). Thus, for five, ten and 15 mating pairs $F_{\text {IS }}$ approximates to $-0.053,-0.026$ and -0.017 , respectively, which are very close to the numerical values. The simulations, however, assume that females contribute equally to the total number of eggs of each fruit, but the actual estimate is for an effective number of mating pairs.

Let us accept the figure of 15 mating pairs contributing progeny to a site. It would be possible, then, to overcome the difficulties with the bootstrap method and build a confidence interval for the $F_{\text {IS }}$ value in the control fruits under the hypothesis that selection has a negligible effect on the allozyme variation. To do this, we generated 500 independent samples that matched the situation for the control fruits, ie, the mating pairs were selected randomly to contribute to 12 breeding sites, and a number of individuals equal to the actual sample size was taken at random per site. Figure 4 shows the distribution of the $F_{\mathrm{IS}}$ values obtained. We find that the probability of $F_{\text {IS }}$ being less than or equal to -0.0687 (ie, the actual value in the control fruits) is 0.162 , and it is clear that we cannot support the hypothesis of a heterozygote excess in the control fruits caused by selection with the evidence from the simulations. 


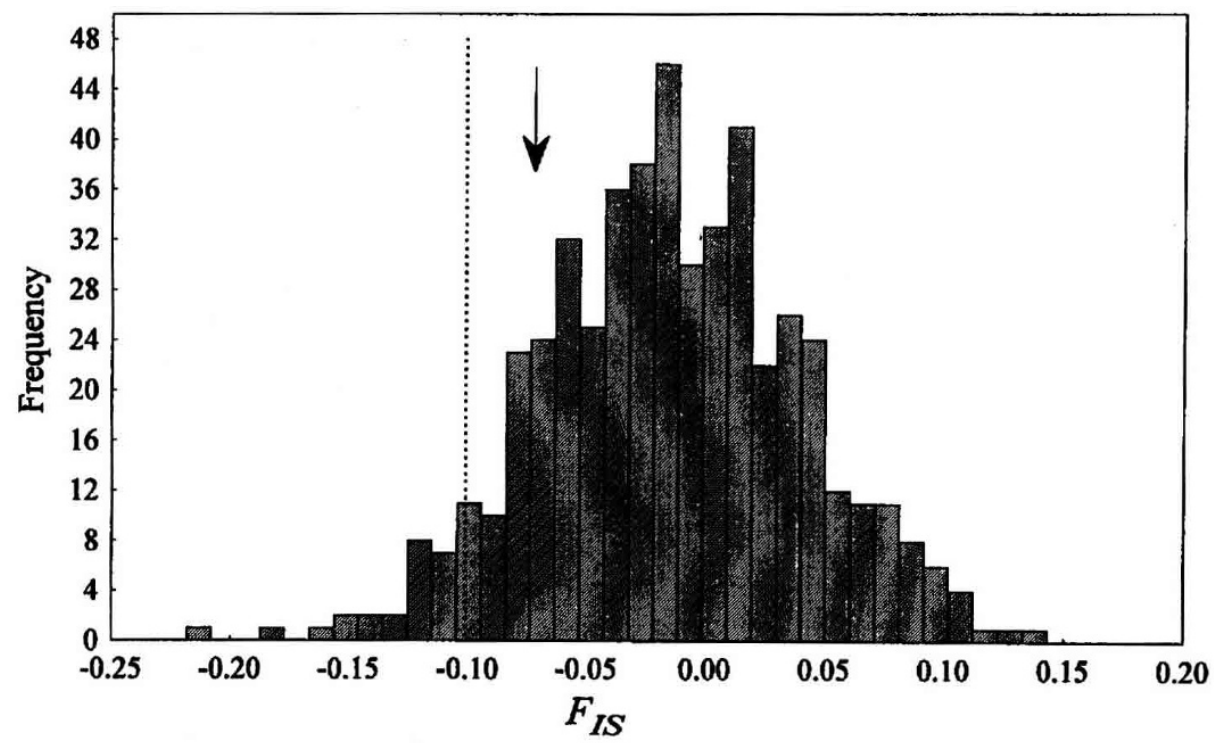

Fig 4. Distribution of $500 F_{\text {IS }}$ estimates obtained from computer simulations that matched the sample sizes in the control fruits. We are assuming that 15 randomly selected mating pairs are contributing to the progeny emerging from a fruit. The one-tailed $5 \%$ rejection region is marked off by the vertical dotted line. The arrow identifies the actual estimate being tested $(-0.0687)$.

\section{DISCUSSION}

We have shown that the larvae of $D$ buzzatii are resource limited in Opuntia fruits, and this species suffers density-dependent mortality in the field (table I). In addition to larval viability, resource limitation also has a significant effect on body size, a trait phenotypically positively correlated with adult fitness components (Santos et al, 1988, 1992; Leibowitz et al, 1995). The relevance of resource structure for expected mating success and/or fertility of the fly is clearly indicated by the substantial differences found in the individual body size due to properties of the breeding sites in which it grew as a larva (Prout and Barker, 1989), and both of these effects can be interpreted as demonstrating that there is a large opportunity for selection under natural conditions. The same conclusion had been previously reached by Grimaldi and Jaenike (1984) for mushroom-feeding Drosophila, which suggests that such phenomena have to be considered as general in natural conditions. It should be noted that the fruits in our experiment were only available for oviposition for at most $108 \mathrm{~h}$. If oviposition continues beyond this time, resource limitation in undisturbed Opuntia fruits may actually be greater than our data suggest.

When resources are scarce, those species (or individuals within a species) with a short developmental period are presumably at a competitive advantage because larvae are more likely to complete development before their patch is exhausted (Bakker, 1961, 1969; Nunney, 1983; Mueller, 1988; Partridge and Fowler, 1993; 
Santos et al, 1994). It is, therefore, interesting that one of the two slow developers in our sample, namely $D$ buzzatii, shows a significant effect of additional food. The numbers of $D$ hydei flies emerging from the Opuntia fruits were too low to obtain meaningful conclusions. Breeding opportunities for Drosophila species in Opuntia sites are frequent during the fruit season (from August to November at Carboneras), and we could hypothesize that interspecific competition would exclude $D$ buzzatii from Opuntia fruits because the most common coexisting species, $D$ simulans, is at a competitive advantage. However, even though the wing length of $D$ buzzatii was significantly negatively correlated with the density of $D$ simulans in $108 \mathrm{~h}$ control fruits, the relative intensities of intra- and interspecific competition cannot be assessed from our data. Some recent experiments on larval competitive effects measured on semi-natural $O$ ficus-indica fruit food at $25^{\circ} \mathrm{C}$ suggest that both $D$ melanogaster and $D$ simulans significantly reduce larval performance of $D$ buzzatii (A Galiana, pers comm 1995)

We can think of Drosophila population structure as consisting of an array of local breeding populations with high extinction and recolonization rates. The fraction of genetic variance due to the sampling effect of colonization among the newly founded populations is $F_{\mathrm{ST}}=\frac{1}{2 N_{\mathrm{e}}}, N_{\mathrm{e}}$ being the effective number of adults breeding on a single patch (Wade and McCauley, 1988). This would be an equilibrium value because the successional changes that take place in the discrete breeding sites are so rapid that there is often time for only a single generation before the patch becomes unusable. Under this simple model, the effect of breeding structure on genetic variation is expected to be uniform over all alleles and loci, whereas natural selection may be expected to act differently on each allele and locus (Lewontin and Krakauer, 1973). Estimates of $F$-statistics (table III) suggest that there is an excess of heterozygotes within, and a substantial differentiation among, limited resource fruits when compared with the values obtained from the supplemented halves. This could be taken as evidence for selection acting in some way on the allozyme variation. However, even though the $95 \%$ confidence intervals for the $F_{\text {IS }}$ estimates do not overlap, the conclusion that both values are statistically different is not warranted (fig 3 ). We would like to point out that comparisons of $F$-statistics is a somewhat indirect way of detecting selection, and other methods might be more appropriate. The present experimental design could, in theory, allow us to estimate both input (from supplemented halves) and output (from control halves) zygotic ratios in natural breeding substrates. Measures of larval viability could thus be obtained in each site from the cross-product estimator (Manly, 1985), together with confidence intervals. However, the number of $D$ buzzatii flies that emerged from the control halves was not large enough to allow meaningful fitness estimates.

In conclusion, our data show that there is density-dependent mortality in the field for $D$ buzzatii, and suggest that about 30 individuals contribute progeny to each fruit. The data do not, however, provide an unambiguous answer with respect to the occurrence of selection on allozyme variation. 


\section{ACKNOWLEDGEMENTS}

We thank B Shorrocks and two anonymous reviewers for constructive criticisms on previous drafts. This work was funded by grant PB89-0325 from the Dirección General de Investigación Científica y Técnica (DGICYT, Spain) to AF, Contract No CHRX-CT920041 from the Commission of the European Communities, and grant CE93-0019 from the DGICYT.

\section{REFERENCES}

Arnold SJ, Wade MJ (1984) On the measurement of natural and sexual selection: theory. Evolution 38, 709-719

Atkinson WD (1979) A field investigation of larval competition in domestic Drosophila. $J$ Anim Ecol 48, 91-102

Bakker K (1961) An analysis of factors which determine success in competition for food among larvae of Drosophila melanogaster. Arch Neerl Zool 14, 200-281

Bakker K (1969) Selection for rate of growth and its influence on competitive ability of larvae of Drosophila melanogaster. Netherl $J$ Zool 19, 541-595

Barbadilla A, Ruiz A, Santos M, Fontdevila A (1994) Mating pattern and fitness component analysis associated with inversion polymorphism in a natural population of Drosophila buzzatii. Evolution 48, 767-780

Barker JSF, Mulley JC (1976) Isozyme variation in natural populations of Drosophila buzzatii. Evolution 30, 213-233

Barker JSF, East PD, Weir BS (1986) Temporal and microgeographic variation in allozyme frequencies in a natural population of Drosophila buzzatii. Genetics 112, 577-611

Betrán E, Quezada-Díaz JE, Ruiz A, Santos M, Fontdevila A (1994) The evolutionary history of Drosophila buzzatii. XXXII. Linkage disequilibrium between allozymes and chromosome inversions in two colonizing populations. Heredity 74, 188-199

Brncic D (1983) Ecology of flower-breeding Drosophila. In: The Genetics and Biology of Drosophila, vol 3d (M Ashburner, HL Carson, JN Thompson Jr, eds), Academic Press, London, 333-382

Crow JF (1958) Some possibilities for measuring selection intensities in man. Hum Biol $30,1-13$

Dytham C, Shorrocks B (1992) Selection, patches and genetic variation: a cellular automaton modelling Drosophila populations. Evol Ecol 6, 342-351

Dytham C, Shorrocks B (1995) Aggregation and the maintenance of genetic diversity: an individual-based cellular model. Evol Ecol 9, 508-519

Fellows DP, Heed WB (1972) Factors affecting host plant selection in desert-adapted cactiphilic Drosophila. Ecology 53, 850-858

Gillespie JH (1991) The Causes of Molecular Evolution. Oxford Univ Press, New York

Gillespie JH, Turelli M (1989) Genotype-environment interaction and maintenance of polygenic variation. Genetics $121,129-138$

Grimaldi D, Jaenike J (1984) Competition in natural populations of mycophagous Drosophila. Ecology 65, 1113-1120

Hedrick PW (1986) Genetic polymorphism in heterogeneous environments: a decade later. Ann Rev Ecol Syst 17, 535-566

Heed WB (1968) Ecology of the Hawaiian Drosophilidae. Univ Texas Publ 6818, 387-419

Hoffmann AA, Nielsen KM (1985) The effect of resource subdivision on genetic variation in Drosophila. Am Nat 125, 421-430 
Hoffmann AA, Nielsen KM, Parsons PA (1984) Spatial variation of biochemical and ecological phenotypes in Drosophila: electrophoretic and quantitative variation. Devel Genet 4, 439-450

Jaenike J, James AC (1991) Aggregation and the coexistence of mycophagous Drosophila. $J$ Anim Ecol 60, 913-928

Jaenike J, Selander RK (1979) Ecological generalism in Drosophila falleni: genetic evidence. Evolution 33, 741-748

Kimura M, Crow JF (1963) The neasurement of effective population number. Evolution $17,279-288$

Labrador M, Naveira H, Fontdevila A (1990) Genetic mapping of the Adh locus in the repleta group of Drosophila by in situ hybridization. $J$ Hered $81,83-86$

Lacy R (1983) Structure of genetic variation within and between populations of mycophagous Drosophila. Genetics 104, 81-94

Leibowitz A, Santos M, Fontdevila A (1995) Heritability and selection on body size in a natural population of Drosophila buzzatii. Genetics 141, 181-189

Levene H (1953) Genetic equilibrium when more than one ecological niche is available. Am Nat 87, 331-333

Lewontin RC, Kojima K (1960) The evolutionary dynamics of complex polymorphisms. Evolution 14, 458-472

Lewontin RC, Krakauer $J$ (1973) Distribution of gene frequency as a test of the theory of the selective neutrality of polymorphisms. Genetics 74, 175-195

Manly BFJ (1985) The Statistics of Natural Selection on Animal Populations. Chapman and Hall, London

MATLAB ${ }^{\circledR}$ Reference Guide (1992) The MathWorks Inc, Massachusetts

Mueller LD (1988) Density-dependent population growth and natural selection in foodlimited environments: the Drosophila model. Am Nat 132, 786-809

Nunney L (1983) Sex differences in larval competition in Drosophila melanogaster: the testing of a competition model and its relevance to frequency-dependent selection. $\mathrm{Am}$ Nat 121, 67-93

Partridge L, Fowler K (1993) Responses and correlated responses to artificial selection on thorax length in Drosophila melanogaster. Evolution 47, 213-226

Prout T, Barker JSF (1989) Ecological aspects of the heritability of body size in Drosophila buzzatii. Genetics 123, 803-813

Quezada-Díaz JE (1993) Estructura poblacional y patrón de apareamientos de la especie cactófila Drosophila buzzatii. PhD diss, Universitat Autónoma de Barcelona, Spain

Quezada-Díaz JE, Santos M, Ruiz A, Fontdevila A (1992) The evolutionary history of Drosophila buzzatii. XXV. Random mating in nature. Heredity $68,373-379$

Raymond M, Rousset F (1995a) GENEPOP Version 1.2, a population genetics software for exact tests and ecumenicism. J Hered 86, 248-249

Raymond M, Rousset F (1995b) An exact test for population differentiation. Evolution 49, 1280-1283

Ruiz A, Fontdevila A, Santos M, Seoane M, Torroja E (1986) The evolutionary history of Drosophila buzzatii. VIII. Evidence for endocyclic selection acting on the inversion polymorphism in a natural population. Evolution 40, 740-755

Santos M (1997) Resource subdivision and the advantage of genotypic diversity in Drosophila. Heredity 78, 302-310

Santos M, Ruiz A, Barbadilla A, Quezada-Díaz JE, Hasson E, Fontdevila A (1988) The evolutionary history of Drosophila buzzatii. XIV. Larger flies mate more often in nature. Heredity 61, 255-262 
Santos M, Ruiz A, Fontdevila A (1989) The evolutionary history of Drosophila buzzatii. XIII. Random differentiation as a partial explanation of chromosomal variation in a structured natural population. Am Nat 133, 183-197

Santos M, Fowler K, Partridge L (1994) Gene-environment interaction for body size and larval density in Drosophila melanogaster: an investigation of effects on development time, thorax length and adult sex ratio. Heredity 72, 515-521

Santos M, Ruiz A, Quezada-Díaz JE, Barbadilla A, Fontdevila A (1992) The evolutionary history of Drosophila buzzatii. XX. Positive phenotypic covariance between field adult fitness components and body size. J Evol Biol 5, 403-422

Shorrocks B (1982) The breeding sites of temperate woodland Drosophila. In: The Genetics and Biology of Drosophila, vol 3b (M Ashburner, HL Carson, JN Thompson Jr, eds), Academic Press, London, 385-428

Siegel S, Castellan Jr NJ (1988) Nonparametric Statistics for the Behavioral Sciences. McGraw-Hill, New York, 2nd ed

Sturtevant AH (1919) A new species closely resembling Drosophila melanogaster. Psyche $16,153-155$

Thomas RH, Barker JSF (1990) Breeding structure of natural populations of Drosophila buzzatii: effects of the distribution of larval substrates. Heredity $64,355-365$

Wade MJ, McCauley DE (1988) Extinction and recolonization: their effects on the genetic differentiation of local populations. Evolution 42, 995-1005

Weir BS (1990) Genetic Data Analysis. Sinauer, Massachusetts

Weir BS, Cockerham CC (1989) Complete characterization of disequilibrium at two loci. In: Mathematical Evolutionary Theory (ME Feldman, ed), Princeton Univ Press, Princeton, 86-110 